\title{
Presidential address \\ The Ideological and Economic Repositioning of Universities
}

\author{
Allan Pitman (University of Western Ontario)
}

\begin{abstract}
A reconceptualization of the human capital value of education as a private good, linked to a market oriented commodification of university knowledge, underpins a repositioning of universities as entrepreneurial enterprises. The implications for universities and the professoriate are explored, with a particular emphasis on the ways in which the institutions and work within them are being redefined. Canadian and Australian experiences are drawn upon.
\end{abstract}

\begin{abstract}
Résumé
Une nouvelle conceptualisation de la valeur du capital humain en enseignement comme un bien privé, relié au savoir universitaire comme des marchandises destinées au marché, étaie une repositionnement des universités comme des entreprises commerciales. L'auteur explore les implications pour les universités et le corps professoral, avec une emphase particulière sur les façons dont les institutions et leurs travaux se redéfinissent. L'auteur se sert des expériences canadiennes et australiennes.
\end{abstract}

\section{The present context}

I wish to locate my remarks in the context of two major developments in the global picture of education. One is the economic relocation of higher education and the transformation of knowledge into an economically grounded export commodity. The other is the UNESCO-led push for Education For All.

\section{Knowledge as an export commodity}

Most of us work in universities, either as faculty or students. We need to recognize the ways in which our teaching and research environments are changing at a very fundamental level.

The 1980s and 1990s saw, in the West, the start of a repositioning of higher education, underpinned by a reinterpretation of the human capital argument. In the 1960s, there was a massive expansion in access to higher education - particularly to university education - based on the arguments of the American economist, Schultz $(1961,1979)$. The logic went that, parallel with the gross domestic product of a country, based upon production and output of goods and services, there existed an economic component based upon the developed capacities of the population. As a consequence of this, it was in the interests of the State to put resources into the development of this dimension of the national 
economy: policy outcomes of this approach included both the expansion of tertiary education and the drastic reduction or abolition of fees for access to such educational development. Thus, parties of both the left and right pursued policies of access to higher education based upon this platform, overlaid with other policies such as those based upon class or racial equity.

The emergence of neoliberal agendas, and governments based upon that philosophic position, were accompanied by a reinterpretation of the idea of human capital. In particular, the location of the capital accumulation stemming from the increase in knowledge was shifted from the realm of the State and population as a whole to that of the individual, with the national accumulation being the aggregation of the gains of the individual citizens. It would be a mistake to see this as a reversible process in the short or medium term, or to identify it purely with political parties of the right. In Australia, it was the Whitlam Labor government that introduced free university education. In the 1990s it was the Keating Labor government that reintroduced fees.

There is an important extension of the logic associated with this redefinition: the industrialization of the system for its delivery and the positioning of education as an export commodity, which we are seeing being exploited by governments in a variety of ways. In Ontario, partially deregulated university fees in various faculties are related to the potential earnings projected for their graduates. In Australia, admission patterns have shifted from being based upon academic criteria alone to the present situation in which 35 per cent of places are available to full-fee paying students. An even more potent application is the recognition of knowledge as a tradable commodity. This is an issue both for reflection and for research by us with a commitment to the issues of comparative and international education.

\section{The increased role of student fees in operating budgets.}

Across the board, student tuition fees have climbed, in both Australia and in Canada. The rationale offered is a revised view of human capital, with the transfer of benefit from the economy as a whole (the 1960s model) to the individual. This has direct implications for funding models for universities, with the introduction of the argument that the student who benefits should bear the cost. One offshoot of the educational capital argument is the attempt to quantify the return on investment by students in universities on an individual basis (Gallagher, 2005, p. 15). The common good, it is argued from this position, only flows in areas such as international competitiveness through the aggregation of the benefits gained by the individuals. In harness with the rise in student tuition fees, the levels of funding of universities flowing from government have undergone radical adjustments over the past decades. Under the Australian Howard Liberal government, there has been no real increase in expenditure on higher education 
for some 15 years. The situation in Canada, through Conservative and Liberal governments, is comparable.

Data from Canada provide insight into how reductions in government contributions have been compensated in large part through an increased reliance on student tuition fees.

The Canadian Association of University Teachers (2005) reports that tuition as a percentage of University operating revenue in the province of Ontario has gone from 16 per cent in 1983 through $20 \%$ (1993) to $37 \%$ in 2003 . For Canada as a whole, the trend is clear, with the percentage of government funding dropping from 82 per cent of operating budget in 1983 to 59 per cent in 2003. Over the same period, the contribution from student tuition has risen from 13 per cent to 29 per cent.

Table 1

Government funding and tuition as share of university operating revenue, Canada

$\begin{array}{cccc}\text { Year } & \text { Government } & \text { Tuition } & \text { Total } \\ 1973 & 79.3 \% & 16.6 \% & 95.9 \% \\ 1983 & 81.8 \% & 12.9 \% & 94.7 \% \\ 1993 & 75.9 \% & 18.4 \% & 94.3 \% \\ 2003 & 59.3 \% & 29.1 \% & 88.4 \%\end{array}$

Source: CAUT, 2005, p. 41.

The greatest changes in funding contribution from government has come at a time of rising student numbers, with the participation rate of 18-25 year olds in university education rising from $16.8 \%$ in $1991-2$ to $18.8 \%$ in $2001-2$.

Another telling insight is gained by looking at the percentage of operating budgets in Canadian universities spent on academic salaries: since 1973 to 1993 , this has declined from $31.5 \%$ (1973) to $20.5 \%$ (2003). This is largely an indicator of rising student/faculty ratios and hence average class sizes. Over the same period, Federal cash transfers as a percentage of GDP have fallen from a 1983 figure of $.40 \%$ and $0.40 \%$ in 1993 , to $0.23 \%$ in 1998 and down to a 2003 contribution of $0.16 \%$ of GDP.

The need to find funding from other sources has encouraged an increasingly aggressive search for students - particularly profitable full-fee paying ones - in the case of Australia, New Zealand and Britain. This recruitment has taken place largely in developing countries.

\section{University knowledge as a commodity}

The emergence of the internationally active university is a development through which we can trace a fundamental shift which is occurring in the location of 
universities as social institutions and a redefinition of the knowledge with which they are associated. The Australian experience is, perhaps, the most graphic example of this phenomenon. An insightful analysis of the Canadian and Australian cases is offered by Nesterova (2006).

\section{International initiatives}

The Australian Vice Chancellors' Committee (AVCC) lists as one of four features of its vision for 2020 that Australian educational exports will position the country in the "global educational revolution". The "symbol" of this objective is that: "Higher education will join 'resources' and 'services' in the top 3 value-adding Australian exports" (Australian Vice Chancellors' Committee, 2002, p. 2). The document goes on to point out that "Australian education services have grown since 1985 to become our $8^{\text {th }}$ largest export income, with the potential to grow further." The AVCC is a private company whose members are the ViceChancellors of thirty-seven Australian universities, one of which is private. It has as its purpose " ... to advance higher education through voluntary, co-operative and co-ordinated action." (Australian Vice Chancellors' Committee, 1999).

The push to internationalize the student body is not new for major universities around the world, particularly at the graduate level: universities such as Stanford, Harvard, Oxford and Cambridge have drawn overseas students to their campuses for a century. What is new is the push beyond seeking the elite among foreign student populations to the recruitment of any qualified student with the capacity to pay the fees. Allied with this have been the dual moves to provide spaces in Australia at home and satellite campuses and, at the same time, to develop arrangements to provide courses in the students' home countries. This latter move is being developed through a range of tactics, from the establishment of campuses operated by the university, and joint ventures with local universities, to subcontracting arrangements with private operators. Many foreign universities engage local private colleges to deliver bridge programs which provide direct entry into second year of degree programs on the home campuses of the universities. The bridge program arrangement is also employed for foreign students in the country of origin of the university.

In parallel with other forms of recruitment in the search for students, there has been a massive growth in the offering of distance education courses. Increasingly, the provision of such courses and programs has become a major arena of competition, as universities struggle to maintain and increase student numbers and the consequent fees. While most of these - mainly on-line programs are aimed at domestic students, they do become part of the mix in the provision of courses for foreign students.

Along with this commodification and marketing comes the exposure to market forces. With a distortion of the student population with respect to both 
reliance on high-fees paying students and program offerings tied to market demand, universities are becoming exposed to the vagaries of the market. Good examples are seen in the history of IT and business courses. Victoria University is an example, with some $70 \%$ of international students enrolled in business

The establishment of teaching facilities overseas is a growing activity: The University of Western Ontario maintains an arm of its Ivey School of Business in Hong Kong. While we may be tempted to suggest that business schools are different, we should also note that another way of looking at it is to recognize that they were simply the first. A look at the New Straits Times in Kuala Lumpur quickly reveals the aggressive intrusion into the Asian education market of universities from Britain, Australia and New Zealand. Indeed, supplements in the New Straits Times promote Australian higher education weekly. Not only is this drive aimed at attracting students to study abroad, but a number of universities are establishing campuses: Monash University has its Kuala Lumpur and its South African campuses.

International full-fee paying students in Australia constitute a growing percentage of enrollments, to the extent that when the so-call Asian flu hit the economies of South East Asia some seven years ago, the industrial sector of the Australian economy most affected was the university industry. The explosion of demand for programs in Information Technology (IT) in the 1990s led to rapid growth of departments to cater internationally; with the collapse of the market due to saturation of the market and the economic problems in south east Asia in the late 1990s the need came to reduce the size of those academic departments. Monash University terminated the employment of approximately half such faculty. The exposure of universities to market forces and their sometimes violent fluctuations contributes to a radically new environment for universities.

\section{The demand imperative}

An analysis of new positions advertised by Australian universities in the last two quarters of 2004 revealed that Health, Management and Commerce dominated the data, with Society and Culture and University Management and Administration positions. A codicil concerning the Society and Culture cluster is the diversity of its constituent parts, with Legal Studies, Psychology, Sociology/Social Studies/Development Studies and Economics to the fore, while disciplines such as Classics, Gender Studies, Australian Studies, and Philosophy languished (McHoul, 2005). The trends seen in Australia in this respect are not unique, as a comparison with Canada (Rosenfeld, 2003) makes clear. At my own institution, 70 per cent of students enrolled in the Faculty of Social Science take courses in the organizational management program.

The implication of these data is that many of the traditional areas of study in the universities are at risk of closure or curtailment as a business/management 
preparation rationale exercises its influence through the program choices of prospective students and the institutions' responses to these market forces in the expansion of offerings and of faculty positions in these areas. Thus the cluster of studies under the general heading of society and culture is being recast away from the classics, philosophy and the like and towards management studies and related disciplines. This is not to deny the traditional role of universities in professional preparation, but rather to draw attention to the relatively narrow focus, which is not only driven by the market, but is itself directed to preparing students to operate in that environment. Further, there has been a proliferation of non university providers, both entirely separate companies and companies established by universities, such as the ill-fated Melbourne University Private (see Cain \& Hewitt, 2004, for the history of this venture).

While on the subject of education-as-industry, it is worth noting that the AVCC sits also as the Australian Universities Industrial Council in order to deal with the workplace negotiations with the national union for academic workers, which is itself a member of the Australian Council of Trades Unions, again from the 1980s. The Universities Industrial Council is a coordinated industrial bargaining unit for the universities as employers in a unionized environment.

The transformations in corporate structures: Industrialization and the creation of the education sector

Increasingly, Canadian university faculty associations are unionizing. The unionization of faculties and their subsequent Australian Council of Trade Unions (ACTU) affiliation in 1980s marked a significant relocation of the university in the Australian social and economic structure. One outcome of these organizational realignments and affiliations has been a fundamental shift in the language in which participation in higher education is discussed. A stark example is the banner for the NTEU (National Tertiary Education Union) 1999 conference, seen in a photograph in the union journal: "One Industry One Union" (Advocate, 2003 , p. 30). The introduction of "merit" and "market" components to salary structures is also worthy of note (Stilwell, 2003).

The advent of the North American Trade Agreement brings this development in higher education into focus for Canada and for Mexico. Education, viewed as an industry with knowledge as its commodity, as packaged as coursework and degree programs, becomes the subject of the trade rules and arbitration procedures of the agreement. One private university, the University of Phoenix, has been active in Canada for some time.

The nature of university work: to be professional

The restructuring of universities and their place within the social/economic framework have the potential to have profound effects on the nature of the work 
of the professoriate and how its members are employed. I have already alluded to this, but believe it requires further elaboration. A useful starting point is to consider the notion of professional work, and how it relates to the university environment. The nature of professorial work and its character as a profession becomes a contested domain. In an earlier study I drew attention to the often contradictory tendencies and their effects on teacher education in eight countries (Pitman, 1993).

A difficulty with the common parlance discussion of professionalism lies in its inability to distinguish between the behaviour of individuals, and the behaviour of members of an occupation agreed to be a profession, from those in other occupations. This can be seen quite clearly by reference to the dictionary definitions of "profession", "professional" and "professionalism". It will be seen that the idea of a professional can be given meaning fairly independently of the idea of a profession.

The Oxford English Dictionary (1971) traces the notion of a profession to its religious roots, as a vocation to which one makes profession. The religious orders then can be taken as an historical benchmark for the search for characteristics that differentiate professions from other occupations. On the other hand, a person may be professional in sport simply by accepting money to engage in it as an occupation. Simply put, the Oxford English Dictionary lists under "professional" the conflicting definitions of being a member of one of the learned professions, and one who engages in an activity for payment that others undertake for pleasure.

Similarly, the use of the term "profession" has become ambiguous:

(It is) Now usually applied to an occupation considered to be socially superior to a trade or handicraft; but formerly, and still in vulgar (or humorous) use, including these (p. 1428).

It is not surprising that by the time the dictionary reaches "professionalism" the definitions are becoming outright contradictory:

1. Professional quality, character, method, or conduct; the stamp of a particular profession.

2. The position or practice of a professional as distinguished from an amateur; the class of professionals (p. 1428).

It is important to pay attention to these ambiguities, as they lie at the heart of much of the debate and policy formation that has occurred. Further, the debate as to whether professional behaviour on the part of professors is manifested in upholding the standards of a profession or in faithfully fulfilling their salaried contractual obligations is paramount. 
I will draw again on the Australian experience. From the 1960s, Australian universities have moved from a collegial model of operation to one based upon some (but not all) of the characteristics of corporations, and on partcommodification of teaching and research (Marginson \& Considine, 2000).

A graphic instance which captured this transformation was seen when the Vice Chancellor of the University of Melbourne was quoted as considering that his institution was no longer a public institution, having seen the level of government budgetary support drop over 25 years from 90 percent to approximately 20 percent by 2005 (Melbourne Age, November 16, 2005). The report continued with information concerning the university's strategic plan to restructure its teaching programs along United States lines, in particular the reduction of undergraduate enrolment and the transfer of professional schools to the graduate sector. This extraordinary claim has a context spanning three decades. During a period of declining government funding support and of restructured faculty/management relations, universities had found it necessary to explore a range of entrepreneurial and private venture operations.

The past two decades have been marked by the intrusion of managerial language into all levels of government-sponsored education systems. Cain \& Hewitt (2004) observe of the University of Melbourne that "... the direction away from the notion of the public university has been driven by management, supported by council, and encouraged by governments. It is the managers who have led the charge for the past fifteen years" (p. 211).

While much of the more radical change has occurred at a time when the (conservative) Liberal Party has held power nationally, it must be pointed out that much of what is reported here had its genesis in policies of the Hawke and Keating Labor governments and consequently have roots back in the 1970s. Much of the reform impetus emerged when the federal Minister of Education was John Dawkins, whose name has become attached to much of what transpired.

The Dawkins reforms came at a time of massive increases in university enrollments, and the very real budgetary problem of how to fund this seismic shift in the Australian university environment. The need for expansion of the budget investment in higher education - particularly in the universities - was becoming critical. One way out of this dilemma came in the government's analysis of the socio-economic backgrounds of the students. A decade previously, the earlier Whitlam Labor government had introduced free university education in order to open up higher education to all classes, and the analysis suggested that, fundamentally, the class mix had not changed over that time. The reintroduction in 1983 of student fees, by the next Labor government under Bob Hawke, was accompanied by the rationale that the stated objective of opening university education to the working classes had not been achieved and the absence of fees was simply a subsidy to the middle class. By creating at the same time an 
innovative deferred income-related loan repayment scheme, not only did the government start to shift the cost of education to the student, but also was able to claim that no student was denied access by inability to pay. There are long term issues concerned with mounting debt repayment problems which will need to be confronted in the future. This was, however, the start of the shift in funding ratios for public universities to a reliance on aggressive pursuit of student fees and other non-governmental funding arrangements. With the change of government to a more right-wing administration, the trend accelerated. Under the Howard Liberal government, there has been no real increase in expenditure on higher education for some 15 years. Thus, the funds for maintaining a status quo and for any degree of growth have increasingly depended on universities becoming entrepeneurial in their activities, particularly in their teaching functions.

\section{Quality in the educational context: The university.}

In a growing number of countries, for example, the United Kingdom, universities are being subjected to so-called quality audits. On the basis of these reviews, which are reduced to a numerical measure, the institutions are ranked. It behoves us to consider just what "quality" means in this context.

\section{Quality in education: What do we mean?}

The Oxford Dictionary helps us to see the difficulty we have in thinking about just what constitutes a quality system of schooling. It is instructive to quote two short sections from the rather lengthy definitions provided in that it identifies certain tensions which exist within the term itself. The Oxford English Dictionary carries a detailed set of definitions of the word "quality". Of particular interest to this paper are the following two extracts, taken from that part which deals with the quality of a thing:

\section{Of things}

7. An attribute, property, special feature or characteristic. Primary, secondary, etc. qualities: see adj.

8. The nature, kind, or character (of something). Now restricted to cases in which there is comparison (expressed of implied) with other things of the same kind; hence, the degree or grade of excellence, etc. (Oxford English Dictionary, 1971, (p. 2383).

These usages date from at least the fourteenth century, as traced by the dictionary's compilers. There is an essential contradiction in the two usages of the word, in that the first definition seeks out that which is unique or different about 
the object; the second focuses upon the commonality between similar objects and claims to evaluate in terms of comparative excellence.

Education systems are under continuing pressures to be reshaped in ways that respond to the aspirations and fears of the societies that they serve. These concerns are grounded in the context of increasingly interconnected world systems that characterize the globalizing trends in communications, trade and discourse. Increasingly, the issue of quality has become a cornerstone of debates, and policy formation in relation to education systems and their reform. This has been coupled with governmental moves to assert greater control and surveillance over the academic activities of educational institutions at all levels. At the university level, the use of rankings such of that compiled by the London Times, based on citation analysis, are among the most important of these. Worthy of note is that governments pay attention to them, and it should be recognized that they are the products of commercial enterprises. Through means such as these, governments try to position themselves internationally through gauging the quality of their educational institutions through comparative processes and common testing/evaluation procedures. At the same time, within nations, the role of public education in the framing of the identity and particular economic character of countries and regions is of central interest at the local level.

Clementina Acedo has identified factors that influence reforms of school systems. I suggest they apply equally to universities and like institutions.

(a) International or regional pressures, such as the general move towards decentralization and school based reform led by International Organizations; or the pressure on Eastern European countries to reform their education systems as a precondition to be accepted in the European Union. [In the university context, the Bologna Process is a good example]

(b) Country specific contextual variables, among them demographic variables, for instance, ease of demographic pressure may allow for quality improvements; or on the contrary, expansion of coverage in elementary education may generate pressures for expansion of the secondary level. Other very important contextual variables are political will and economic growth that would allow or become obstacles for educational change.

(c) But specific changes in educational policies varied also depending on other contextual variables such as the institutional history of each education system, the labor market structures that make specific requirements to the system and the ways in which secondary education represents or not a path of social opportunity (Acedo, 2007).

Here we see the tension between the local and the global; between quality as character and quality as a comparison of worth. 


\section{Quality and accountability}

It is a commonplace today to see reports of the comparative "excellence" of school systems around the world. These reports draw heavily upon measures obtained from studies such as the Trends in Mathematics and Science Study (formerly the IEA study of 1969, then Second international MSS and Third International Mathematics and Science Study). The name change is significant in that it signals the institutionalization of the series of tests as a continuing - indeed continuous process. The other, more obvious, salient feature is that the measure of quality is codified in terms of a narrow performance measure in a narrow slice of the curriculum: mathematics and science.

In recent years we have seen this benchmarking spread to the university sector (see Turner, 2006a, 2006b). In a number of countries, "league tables" are produced - in Canada, by Maclean's magazine and by the Globe and Mail newspaper; in Britain by the Guardian and Daily Telegraph. Turner makes a trenchant point about these quality measures by introducing a defensible alternative heuristic which largely stands the generally accepted rankings on their heads. Further, if we refer back to my duality of meaning of "quality", it would appear that these accountability measures and quality outcomes militate against diversity and the maintenance of the quality(ies) that make a university unique, pushing for a uniformity of scope and method in both teaching program and in research agendas.

\section{The press for Education For All and its implications}

An ambitious agreement was reached by which a priority for UNESCO should be to push for an elementary education for every child in the world by 2015. The Education for All initiative has undergone modifications and realignments since its inception, but has remained the major international program at a time when the United Nations has been subject to pressures for a comprehensive overhaul of its organization and how its component parts interrelate. While the time frame of 2015 increasingly looks unattainable, the project continues. Funding is of course an issue, not least in the context of the necessary emphasis being given to the fight against the spread of AIDS.

I want to mention developments at UNESCO here, and I will try to tie some of the implications back in with what I have to say later. The recommendations in the draft two year 2008-2009 policy statement of UNESCO sets out how educational programs are to be focused and shared among its agencies: UIS coordination of UN projects; International Institute for Educational Policy (IIEP) country planning and field support; International Bureau of Education (IBE) promoting basic education EC-12; UIL and UNEVOC higher education. 
The biennial sector program priorities 2008-2009 are:

1. Ensuring global coordination and support for national leadership (principal priority), with a focus on effective global coordination to achieve EFA at the country level; capacity building in policy and planning at the country level; and increased participation in the common country programming processes.

2. From access to success through quality education for all, with focus upon standards, good practices and policies on access (EC to HE) with an emphasis on secondary, technical and vocational education; promotion of the right to quality formal and non-formal education; curriculum and textbook development (including content and values issues); development of Literacy for Empowerment (LIFE) country programmes; improvement of teacher education in sub-Saharan countries; the Global Initiative on HIV/AIDS; the strategic and effective use of ICTs in education, particularly in policy development, higher education and the professional development of teachers and non-formal education. (UNESCO)

The implications from initiatives such as Education For All emerge close to home. The UNESCO policy emerges from the consensus of its member states, which then adopt and adapt its detail both with respect to internal initiatives and to their foreign funding policies. What is funded is what there is to be researched and evaluated. So a field of possibilities is inscribed for researchers. One implication of initiatives such as EFA links directly to the capacity of low income countries to develop an adequate infrastructure in its higher education sector, thus opening the door further to the entrepreneurial universities of the developed nations.

\section{Education research: Possibilities and potential threats}

As universities are repositioned as units in the economy, dealing in a tradable commodity, the pressures on research may well intensify in problematic ways. The funding of research is always to a large degree priority driven. The implications are both related to the substance of educational research and to the favoured methodologies.

The relation between research and program evaluation is an issue in the field of international education research. In particular, the research community is not unanimous in setting the boundaries between what constitutes research and what is evaluation, of programs and the like. To what degree can good evaluation work be regarded as case study?

The positioning of research within the geography of power relations and interests becomes important here. If I draw again on the duality of meaning in the 
term "quality" as an example of a focus for study, then we are impelled in different methodological directions. On the one hand, research based on universal indicators lead us to assumptions of desired similarities and comparisons of relative worth; if our concern is with the capacity of a university to respond to particular and local economic, cultural and other aspirations, then we are impelled to argue for diversity of both focus and methodology.

\section{Research as a commodity}

Every Australian university has revised its intellectual property statutes to protect their marketable properties arising from research by faculty. The delineation of the use of time and facilities of the university as opposed to work done out of university time and off the premises has become an issue of major economic importance to the universities. In Canada, the issue is one of current tension.

As research has come to be seen as outcome driven, with a commodity value attached, universities have been motivated to seek ways to close the gap between basic research and the development of advances into commercial or industrial products. One common strategy has been the development of research parks, on or adjacent to university campuses.

There are very real implications for the type of research that will be privileged within this new university environment. The danger is, I believe, that output-driven retailable research which flows from a diminished scope of economically viable units within the entrepreneurial university institution will come to dominate, at the expense of critical, intellectually and politically challenging endeavours. This will represent a loss to the whole of society, not simply to the higher education community.

I have no answers, but, I hope to stimulate focused discussion of the issues raised.

\section{References:}

Advocate. Journal of the National Tertiary Education Union 10(3), 30

Acedo, C. (2007). Comparing and Contextualizing Secondary Education Reforms in Developing Countries in the Nineties: Responding to Demands for Equity, Quality and Relevance? Paper presented, Annual Meeting of the Comparative and International Education Society, Baltimore.

Australian Vice Chancellors' Committee (1999)

Australian Vice Chancellors' Committee (2002) Positioning Australia's universities for 2020. An AVCC policy statement. Canberra: Author. 
Cain, John \& Hewitt, John (2004). Off course. From public place to marketplace at Melbourne University. Melbourne, Australia: Scribe Publications.

Canadian Association of University Teachers (2005). CAUT almanac of post-secondary education 2005.Ottawa: Author.

Gallagher, Michael (2005). Reversing the slide. Australian Universities Review 48(1), 1015.

Mc Houl, Alec (2005). Advertising change. Australian Universities Review 48(1), 24-27.

Marginson, Simon \& Considine, Mark (2000). The enterprise university. Power, governance and reinvention in Australia. Cambridge, England: Cambridge University Press

Melbourne Age (2005, November 16). Halls of learning prepare for sacrifice. From www.theage.com.au/news/national/halls-of-learning-prepare-tosacrifice/2005/11/16 (accessed 11/12/2005).

Nesterova, G. (2006). Internationalization, globalization and student recruitment. Paper presented at the Annual Conference of the Canadian Society for the Study of Education.

Oxford English Dictionary (1971). The compact edition of the Oxford English Dictionary. Oxford: Author.

Pitman, A. (1993). Centralised control and teacher education in Australia. In T. Popkewitz (Ed.), Changing patterns of power: Social regulation and teacher education reform in eight countries. Albany, N.Y.: SUNY Press, 347-368.

Rosenfeld, Mark (2003). Canuck-Do higher education. Australian Universities Review 46(1), 24-31.

Schultz, T. (1961) Investment in human capital. American Economic Review. 51; 1-17.

Schultz, T. (1979) Lecture to the Memory of Alfred Nobel. December 0, 1979. From:

http://ca.geocities.com/econ_0909meet/schultz-lecture.html. Accessed 11 December 2007.

Stilwell, Frank (2003). Markets in merit ... or merit in markets? Australian Universities Review 46(1), 13-16.

Turner, D. (2006a). World university rankings. Unpublished paper, Learning and Teaching Office, University of Glamorgan.

Turner, D. (2006b). Benchmarking universities: The Canadian case. Unpublished paper, Learning and Teaching Office, University of Glamorgan.

Allan Pitman is an Associate Professor at the Faculty of Education, the University of Western Ontario.

He was President of the Comparative and International Education Society of Canada from 2005 to 2007. He can be contacted at pitman@uwo.ca 